\title{
Employees Aren't Factory Slaves: Factors Determining Work Demand and Implications for HRM Practices
}

\author{
Navaneethakrishnan Kengatharan ${ }^{1}$ \\ ${ }^{1}$ Faculty of Management Studies and Commerce, University of Jaffna, Sri Lanka \\ Correspondence: Navaneethakrishnan Kengatharan, University of Jaffna, Sri Lanka.
}

Received: August 2, 2019

doi:10.5430/rwe.v10n3p147
Accepted: October 8, 2019

Online Published: October 9, 2019

\begin{abstract}
Although a plethora of studies on factors determining work demand have been investigated in the West, the Western findings cannot be directly applied to another cultural context and there is still rather constraint studies in collectivist cultural nations. Drawing on the conservation of resources theory and Hofstede's cultural framework, the present study aims to fill a lacuna by identifying factors determining work demand in a collectivist cultural context. Anchored in ontological and epistemological assumptions, the study employed hypothetic-deductive approach with a survey strategy. Data were garnered from randomly selected 569 employees working in the banking sector with the aid of a self-administrated questionnaire. The results disclose that males work longer hours and experience greater work demand than females. The study further reveals the predictors of work demand: working hours had shown the largest impact, followed by tenure, gender, income, formal work-life policies and supervisory status. The present study questioned the worthiness of the equal policies for both men and women in the workplace and emphasised the needs for gender-based HR policies. On balance, the study pushes back the frontiers of work-family literature and becomes a springboard to future scholarly works.
\end{abstract}

Keywords: work demand, work-life policies, supervisory status, conservation of resources theory, Hofstede's cultural framework

\section{Introduction}

In more recent times, studies on work and family lives have been an increasing global focus and blossomed into multidisciplinary fields (Shockley et al., 2017). Work and family are inextricably interwoven in human life and work generates income essential for family functioning. Nonetheless, greater work demand is detrimental to organisation, individual and society such as work-family conflict, poor job performance, job/family dissatisfaction, fatigue, distress, frustration, turnover intentions, and poor employee wellbeing (e.g. Annor \& Burchell, 2018; Kodom-Wiredu, 2019; Sirgy \& Lee, 2018) and consequently, studies emphasise on the importance of understanding factors determining work demand (Boyar, Carr, Mosley, \& Carson, 2007). Although there are a plethora of studies on work demand in the context of western culture, a dearth of such studies have been investigated in South Asian context (Boyar et al., 2007; Shaffer, Joplin, \& Hsu, 2011). The factors determining work demand and its magnitude are subject to variation in national context such as labour laws, culture, workplace relationship, position of the women in the society, economic stability of the country etc. and therefore, findings from one study cannot be generalised to another dissimilar context (e.g. Annor \& Burchell, 2018; Hassan, Dollard, \& Winefield, 2010). Consequently, the present study aims at investigating the factors determining work demand in Sri Lankan context as a microcosm of collectivist cultures in South Asia.

Drawing on Hofstede's dominant cultural framework, Sri Lanka that is similar to India is a large power distance country. Power distance is "the extent to which the less powerful members of institutions and organizations within a country expect and accept that power is distributed unequally" (Hofstede, Hofstede, \& Minkov, 2010, p.61). Moreover, Hofstede et al. (2010) suggest that unequal relationships between superiors and subordinates and hierarchical systems are more prevalent in a large power distance country. The hierarchical system engenders large numbers of supervisory personnel and the boss is a "benevolent autocrat" or "good father" where employees are afraid of disagreeing with their superiors and taking extra burdens giving more pressure at the workplace (see Jin, Ford, \& Chen, 2013). Moreover, the relationships between superior and subordinate are emotional. Thus, the employer-employee relationship is said to be moral like a family link, and thus relationships prevail over tasks. Albeit these factors 
potentially influence work demand, studies on the factors determining work demand in collectivist cultures remain agnostic.

Moreover, the way work-family has been studied has changed over the years. Families are increasingly diverging from the traditional male-breadwinner and female-homemaker model as women are increasingly drawn into the labour market and raise their aspirations for educational attainment, careers and financial independence (Lafreniere \& Longman, 2008). However, the role of men and women in balancing work and family in less developed economies has not been explored. Therefore, a detailed study investigating the factors influencing work demand would be seminal in theorizing and developing HRM policies to manage work demand in this context.

Sri Lanka, one of the South Asian countries, is a culturally dissimilar country in comparison with individualist cultural nations, embedded many indigenous characteristics such as dominance of patriarchy, traditional gender role ideology, the dependency nature of relationship between employer-employee, long working hours, and national characteristics (such as laws, income, women's labour force participation, education and household size). According to Department of Census and Statistics (2013), 68.8\% of employees were working more than 40 hours in Sri Lanka and average monthly income was low (Rs. 25 778; Department of Census and Statistics, 2013). In developing countries, the rate of changes in macro-variables such as economic, technological, social and legal creates more pressure for productivity at work leading to greater work demand (Joplin, Shaffer, Francesco, \& Lau, 2003). Moreover, organisational work-life policies are in an embryonic stage in Sri Lanka. Therefore, Sri Lanka is a good case on these cultural footing.

On balance, anchored in the conservation of resources (COR) theory (Hobfoll, 1989) together with Hofstede's cultural framework (Hofstede et al., 2010), the present study fills a void by identifying factors determining work demand in a collectivist cultural context. This study contributes to the extant literature in many ways. Primarily, by identifying factors determining work demand in a neglected collectivist culture, the study adds to the work and family literature. Consequently, it behoves practitioners and policymakers to introduce well-thought-out strategies to ameliorate the burden of work demand and its knock-on effect on organisational/individual outcomes.

\section{Literature Review}

Yang, Chen, Choi, and Zou (2000) define work demand as "pressures arising from excessive workloads and typical workplace time pressures such as rush jobs and deadlines" (p.114). Work demand is as role responsibilities in which pressures that originate from both the individual (personal goals) and the working environment and therefore, work demand is an intensity of responsibility within the work domain (Boyar et al., 2007; Haar, Sune, Russo, \& Ollier-Malaterre, 2019). Drawing on role theory, COR, resource drain theory and JD-R, earlier studies reported the negative consequences of work demand on employees, organisations and families such as WFC (Annor \& Burchell, 2018), stress (Michel, Kotrba, Mitchelson, Clark, \& Baltes, 2011), turnover intentions (Annor \& Burchell, 2018) and adverse health effects like pains and strain (Kodom-Wiredu, 2019). For instance, Lu, Gilmour, Kao, and Huang (2006) conducted a cross-cultural study of work/family demands, WFC, and wellbeing, on samples of full-time employees in Taiwan and the UK. The results revealed a positive relationship between work demand and WFC both in Taiwan and the UK. Interestingly, Choi (2008) confirmed a negative effect of work demand on life stress among Chinese employees. Similarly, Michel et al. (2011) found employees with greater job responsibilities lead to more stress. Yang et al. (2000) found higher work demand among Chinese employees than American employees implying that Chinese are sacrificing a greater amount of family time for work for the sake of gaining long term profit. From a large corpus of studies, the major determinants of work demand include tenure, working time, supervisory status, reporting status, education, income and work-life policies (e.g. Boyar, Maertz, Mosley, \& Carr, 2008; Michel et al., 2011). Nonetheless, such factors affecting work demand are subject to country-culture specific nature and thus earlier research studies report varying degrees of work demand across countries (Annor \& Burchell, 2018). Therefore, the study fills hiatus by examining factors determining word demand in the context of a neglected cultural nation, Sri Lanka.

\subsection{Working Hours}

Working more hours is a syndrome of more work demand in general (Boyar et al., 2008; Haar et al., 2019), nonetheless, the perception of high demand and its consequences are hinged on national variation including availability of the workplace and family supports, government supports, cultural differences, and macro-environmental factors (Shockley et al., 2017). For instance, individuals in collectivist culture view work as a means to improve family well-being but in contrast, people are achievement-oriented in individualist culture and therefore, the perceptions of work demand cannot be interpreted in the same way in both cultures (Shockley et al., 2017; Syed, Arain, Schalk, \& Freese, 2015). Also, variation in legislation concerning working time would appear to 
be particularly important. Several findings show that working long hours serious affect the balance between work and family (e.g. Russell, O'Connell, \& McGinnity, 2009) and some studies found that men tend to report more hours than women (e.g. Cousins \& Tang, 2004; Martinengo, Jacob, \& Hill, 2010). For instance, Cousins and Tang (2004) conducted a study on the Netherlands, Sweden and the UK to find out working time and the experience of WFC. Working hours were different in three different countries. Males working hours were 40.5 hours, 41.7 hours and 43.5 hours per week respectively in the Netherlands, Sweden and the UK. Correspondently, females working hours were 26.0 hours, 36.5 hours and 29.1 hours per week respectively. According to the Department of Census and Statistics (2003), 68.8\% of employees were working more than 40 hours per week in Sri Lanka. It is thus obvious that the gap between men's and women's average working hours is much dissimilar across many countries reflecting national differences (i.e. employment law, tradition, economic status and culture). Nonetheless, the relationship of working hours on work demand would not be expected to produce a similar impact on nations with collectivist cultures and individualist cultures owing to the influence of extended family members as well. Therefore, It can be hypothesised that:

H1a: Gender will have a significant impact on work demand

H1b: Males will spend longer working hours than that of females

H2: Working hours will be positively related to work demand

\subsection{Education and Income}

According to Sok, Blomme and Tromp (2014), the term higher education refers to employees who have completed a bachelor or master level educational programme. Many studies assume that the highly educated tend to hold professional jobs that generate more income and pressure and thus they experience greater work demand than the less educated (e.g. Mennino, Rubin, \& Brayfield, 2005; Nomaguchi, 2009). Schieman and Glavin (2011) found that education was associated with higher work demand because the highly qualified employees occupy higher status jobs with more pressures, responsibilities and accountability.

The level of pay is strongly dependent on justice theory: distributive justice (what they get) and procedural justice (how it is given) (e.g. Colquitt, Conlon, Wesson, Porter, \& Ng, 2001; Sweeney \& McFarlin, 1993). A few studies conducted in the past have established a positive linkage between pay level and work demand (e.g. Bhave, Kramer, \& Glomb, 2013; Boyar et al., 2008). By and large, income increases the level of responsibilities and thereby experiencing more work demand (Boyar et al., 2008' Michel et al., 2011). Notwithstanding, the nature of the relationships of education and income with work demand has not been established in collectivist culture leading to pose a hypothesis that:

H3: Education will be positively related to work demand

H4: Income will be positively related to work demand

\subsection{Job Status and Tenure}

Employees with supervisory positions are more responsible than employees who do not hold supervising roles (Boyar et al., 2008; Frone, 2000). Supervisors are taking responsibilities of their subordinates in getting things done and monitoring activities. Therefore, supervisors are held accountable and thus might experience greater work demand (Boyar et al., 2008; Frone, 2000; Michel et al., 2011). On an equal footing, employees with longer tenure would expect to experience less work demand in comparison with less experienced employees as experienced employees become attuned to the work role they perform. Thus, it can be hypothesised that:

H5: Supervisory status will be positively related to work demand

H6: Tenure will be positively related to work demand

\subsection{Work-Life Policies}

Since work demand/WFC causes many negative outcomes for both organisation and family, organisation responsiveness to work-family issues is of significant importance. In the 1990s, large numbers of organisations started fashion ways to accommodate family obligations of employees and employers focused on maternity and parental leave, child and dependent care programmes, alternative work schedules, work stations, employee assistance and relocation programmes (e.g. Zedeck \& Mosier, 1990; Goodstein, 1995). The wide range of responses designed to attenuate work demand/WFC now include temporal and operational flexible work options (e.g. Allen, 2001; Baltes, Briggs, Huff, Wright, \& Neuman, 1999), compressed week (e.g. Baltes et al., 1999), financial work-family benefits (e.g. Milliken, Martins, \& Morgan, 1998), informal work accommodation such as rearranging work schedules, taking 
work home, bringing children to work (e.g. Behson, 2002), childcare (e.g. Goff, Mount, \& Jamison, 1990), eldercare assistance (e.g. Goodstein, 1995), and telecommuting (e.g. Bailey \& Kurland, 2002). However, these formal work-life policies are very rare in less developed countries. Beyond these formal policies, informal practices, for instance, allowing lateness to work or early going home to deal with family problems could also be available at superior discretion in organisations. Thus, it would be envisaged that formal and informal organisational policies will influence work demand. Nonetheless, the influence of work-life policies has not been hitherto explored and therefore, it can be hypothesised that:

H7: Work-life policies will be negatively related to work demand

\section{Methods}

\subsection{Sampling and Subjects}

Respondents for this study were selected from a higher status occupation, banking. Since higher status occupations are characterised by large amounts of responsibility, longer working hours, tight working schedules and high pay, they might experience high levels of work demand (e.g. Schieman, Whitestone, \& Van Gundy, 2006). The selection of banking organisations was chosen in terms of the number of branches, employees, business performance and widespread operations (presence nationwide) to cover the range of variations in the banking sector as resided in the 2012 Fitch rating report (Thalgodapitiya \& Bhoumik, 2012). This study employed a non-probability sampling, convenience sampling for selecting branches of all 12 banks by virtue of accessibility and time, and the sampling technique often used in management and business research (Blumberg, Cooper, \& Schindler, 2008). Once branches were chosen, 843 potential respondents were randomly selected according to the proportion of employees working in each bank. Of which, 582 were returned the questionnaire, yielding a return rate of $69 \%$. Of the returned questionnaires, unfortunately, a few important questions were left blank and these were excluded from the study. Finally, the sample made up of 569 respondents yielding a rate of $67 \%$ of distributed.

\subsection{Measures}

Work demand was assessed using three items (a) I feel like I have a lot of work demand (b) I never seem to have enough time to get everything done at work and (c) I have a lot of responsibility at work (see Boyar et al., 2007). Respondents were asked to rate the extent to which they agree or disagree on each statement using a five-point Likert scale from strongly disagree (1) to strongly agree (5). The reliability coefficient Cronbach's alpha for work demand was 88 .

Working hours were measured in terms of number of hours worked per week. The question that asked, "How many hours do you work in a week?" Similarly, tenure by number of years and reporting by number of employees were assessed as continuous variables. Coding system was applied to measure other variables: Supervisory role (1=No; $2=$ =es); Education (1=Basic; $2=$ Higher); income (1=Low; $2=$ High); Type of bank (1=Multinational bank; $2=$ Local bank); Formal work-life policies ( $1=\mathrm{No}$; $2=\mathrm{Yes})$; Informal work-life policies $(1=\mathrm{No} ; 2=\mathrm{Yes})$; and Gender (1=Male; $2=$ Female).

\section{Results}

As a caveat, fundamental assumptions of linearity, homoscedasticity and normality were examined. The most widely used diagnostic measures of multicollinearity are investigated based on VIF (Variance inflation factor) and tolerance. As can be seen in table 4, VIF values are all well below 10 (maximum VIF value is 2.10) and similarly all tolerance statistics are well above 0.2 (minimum value of tolerance 476 ) indicating no multicollinearity between predictors suggesting that the model is capable of assessing the individual importance of each predictor. The plot of *ZRESID against *ZPRED, a histogram and normal probability plot of the residuals were examined and the results have met the assumptions of linearity, homoscedasticity and normality (See Figure 1). In addition, the independent error (i.e. the residuals are independent) is another important assumption of regression analysis and that can be measured using the Durbin-Watson test. As a rule of thumb, a value between 1 and 3 is acceptable (Field, 2013) and in this case, its value 1.847 (Table 2) is indicating that any errors in regression are independent. 

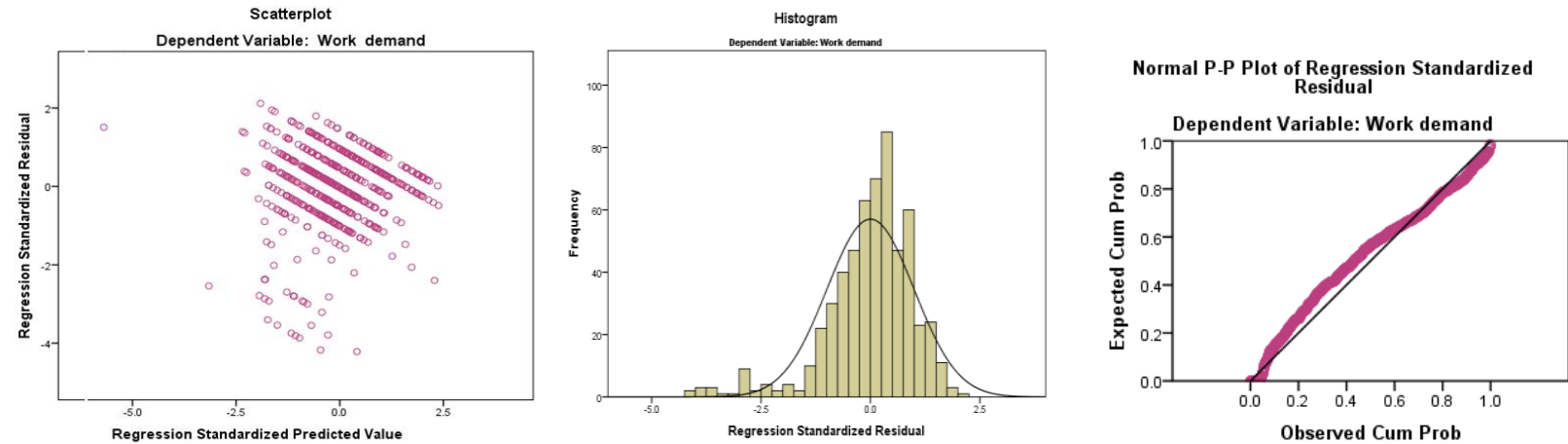

Since the potential bias of the nonresponse can affect generalisability of the findings and 33\% of nonresponse rate warranted the investigation of nonresponse bias (e.g. Dooley \& Lindner, 2003; Werner, Praxedes, \& Kim, 2007), scrupulous attention has been paid on its investigation. The nonresponse bias was examined by dint of "surrogate" method (Wallace \& Mellor, 1988). This method measures nonresponse bias from the known information of sampled data based on the speed of responses by comparing early respondents to that of late respondents. In this study early is defined as $15 \%$ of first received responses $(N=85)$ and the late is $15 \%$ of last received responses. Results showed that there is no significant difference between early and late responses of the prime variables investigated, at $5 \%$ significance level $(p<0.05)$ : Work demand $t(168)=1.88, p=.06)$; working hours $t(168)=.82, p=.42)$; Tenure $t(168)=.34$, $p=.74)$; Work-life policies $t(168)=1.25, p=.21$ ). Consequently, this study did not portend any form of nonresponse bias and hence the results of the study can be generalisable without any cautions.

Anchoring on theoretical and empirical findings, the potential variables expected to be associated with work demand are explored. The correlations between such potential predictors and work demand are presented in Table 1.

As can be seen in Table 1, working hours per week $(r=.47, p<0.01)$ has the strongest positive association with work demand whereas being female has the strongest negative association $(r=-.26, p<0.01)$ with work demand. Furthermore, of the potential predictors, supervisory role $(r=.17, p<0.01)$, number of employees reporting $(r=.21$, $p<0.01)$, tenure $(r=.10, p<0.01)$, high level income $(r=.20, p<0.01)$, local banks $(r=.11, p<0.01)$ were all weakly positively associated with work demand. However, formal work-life policies $(r=-.13, p<0.01)$ was weakly negatively associated with work demand. Educational qualifications and informal work-life policies were not significantly associated with work demand.

Table 1. Correlations between predictive variables of work demand

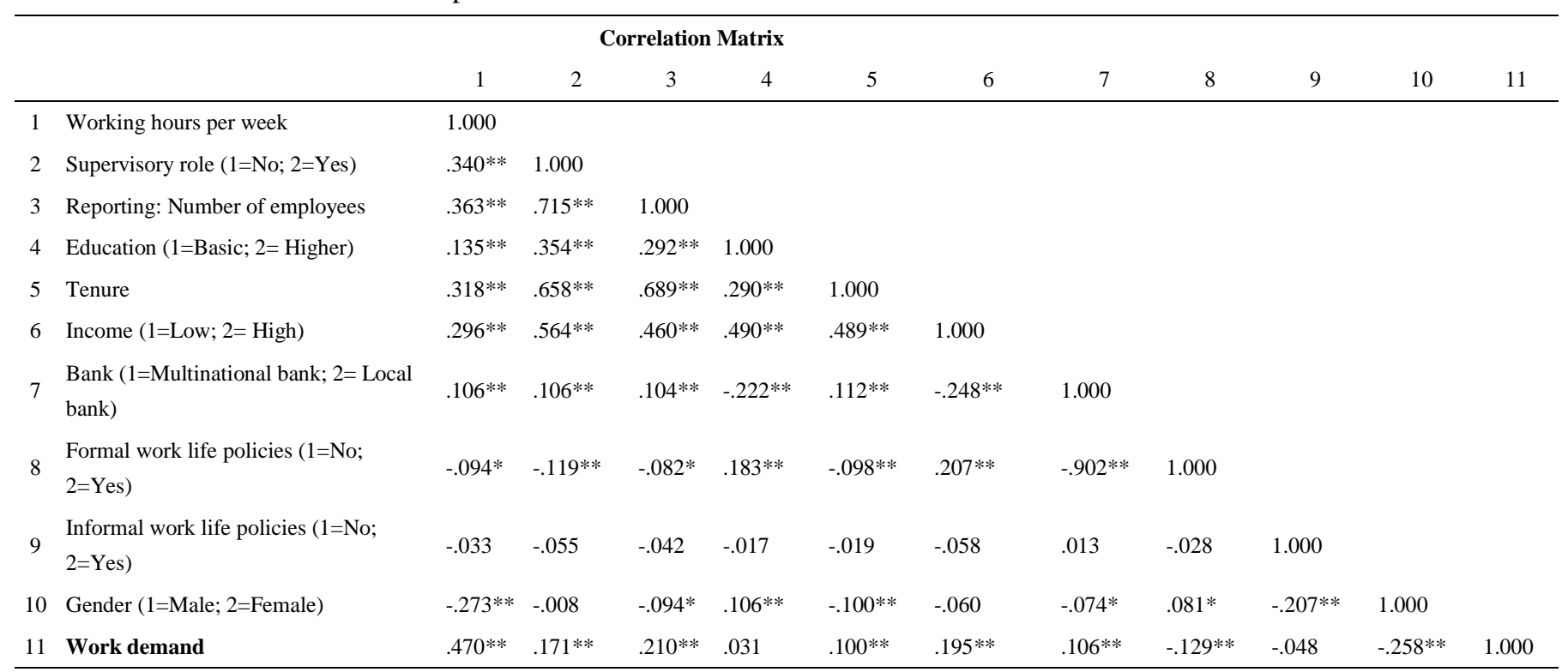

** Correlation is significant at the 0.01 level (1-tailed). * Correlation is significant at the 0.05 level (1-tailed). 
The factors contributing to work demand was examined using stepwise multiple regression analysis which is the most popular sequential approach to variable selection and to examine the contribution of each independent variable and thus facilitates addition or deletion of variables at each stage (Field, 2013). The results revealed a six variable solution that excluded informal work-life policies and educational qualification as insignificant contributions to the model. Table 2 depicts the variance explained by each of these predictor variables.

Table 2. Model summary: Predictors of work demand ${ }^{\mathrm{g}}$

\begin{tabular}{cccccc}
\hline Model & $R$ & $R$ Square & Adjusted $R$ Square & Std. Error of the Estimate & Durbin-Watson \\
\hline 1 & $.470^{\mathrm{a}}$ & .221 & .219 & .69760 & \\
2 & $.489^{\mathrm{b}}$ & .239 & .236 & .68999 & \\
3 & $.495^{\mathrm{c}}$ & .245 & .241 & .68787 & \\
4 & $.502^{\mathrm{d}}$ & .252 & .247 & .68527 & \\
5 & $.514^{\mathrm{e}}$ & .265 & .258 & .68000 & $\mathbf{1 . 8 4 7}$ \\
6 & $.521^{\mathrm{f}}$ & .271 & .264 & .67749 & \\
\hline
\end{tabular}

a. Predictors: (Constant), Working hours

b. Predictors: (Constant), Working hours, Gender

c. Predictors: (Constant), Working hours, Gender, Formal Policies

d. Predictors: (Constant), Working hours, Gender, Formal Policies, Income

e. Predictors: (Constant), Working hours, Gender, Formal Policies, Income, Tenure

f. Predictors: (Constant), Working hours, Gender, Formal Policies, Income, Tenure, Supervisory status (how many reporting)

g. Dependent Variable: Work demand

As seen in Table 2, the inclusion of six variables explains $27.1 \%$ of the variance (Model 6: $R^{2}=.27$ ) in work demand and the effect size of Cohen's $f^{2} .37$ indicating large-sized effect. Cross-validation of a regression model indicating the accuracy of the model in a different sample is necessary (Field, 2013) and thus Stein's formula applied with a sample of 569 and six predictors. The value of Stein's equation is $25.3 \%$ which is closer to the observed value of $R^{2}(.27)$ ensuring that the cross validity of the model.

Table 3. ANOVA- Predictors of work demand

\begin{tabular}{llccccc}
\hline \multirow{2}{*}{ Model } & & \multicolumn{3}{c}{ ANOVA $^{\mathbf{g}}$} & & \\
& & Sum of Squares & df & Mean Square & F & Sig. \\
\hline 1 & Regression & 78.072 & 1 & 78.072 & 160.426 & $.000^{\mathrm{a}}$ \\
& Residual & 275.932 & 567 & .487 & & \\
& Total & 354.004 & 568 & & & \\
2 & Regression & 84.542 & 2 & 42.271 & 88.790 & $.000^{\mathrm{b}}$ \\
& Residual & 269.461 & 566 & .476 & & \\
& Total & 354.004 & 568 & & & \\
3 & Regression & 86.663 & 3 & 28.888 & 61.052 & $.000^{\mathrm{c}}$ \\
& Residual & 267.340 & 565 & .473 & & \\
& Total & 354.004 & 568 & & & \\
& Regression & 89.153 & 4 & 22.288 & 47.463 & $.000^{\mathrm{d}}$ \\
& Residual & 264.851 & 564 & .470 & & \\
& Total & 354.004 & 568 & & & \\
& Regression & 93.676 & 5 & 18.735 & 40.518 & $.000^{\mathrm{e}}$
\end{tabular}




6 \begin{tabular}{lccccc} 
6otal & 354.004 & 568 & & & \\
Regression & 96.048 & 6 & 16.008 & 34.876 & $.000^{\mathrm{f}}$ \\
Residual & 257.955 & 562 & .459 & & \\
Total & 354.004 & 568 & & & \\
\hline
\end{tabular}

a. Predictors: (Constant), Working hours

b. Predictors: (Constant), Working hours, Gender

c. Predictors: (Constant), Working hours, Gender, Formal Policies

d. Predictors: (Constant), Working hours, Gender, Formal Policies, Income

e. Predictors: (Constant), Working hours, Gender, Formal Policies, Income, Tenure

f. Predictors: (Constant), Working hours, Gender, Formal Policies, Income, Tenure, Supervisory status (how many reporting)

g. Dependent Variable: work demand

As shown in Table 3, the value of $F$ statistic is highly significant for all six models: $F(567)=160.43, p<.001$ ), $F(566)=88.79, p<.001), F(565)=61.05, p<.001), F(564)=47.46, p<.001), F(563)=40.52, p<.001)$ and $F(562)=34.88$, $p<.001)$ respectively, indicating initial model significantly improved the ability to predict work demand and thus model 6 was chosen as the best model. Coefficients of the predictors determining work demand are presented in Table 4.

Table 4. Unstandardized Coefficients and Standardized Coefficients of the predictors of work demand

\begin{tabular}{|c|c|c|c|c|c|c|c|c|}
\hline \multicolumn{9}{|c|}{ Coefficients $^{\mathrm{a}}$} \\
\hline \multirow[b]{2}{*}{ Model } & & \multicolumn{2}{|c|}{$\begin{array}{l}\text { Unstandardized } \\
\text { Coefficients }\end{array}$} & \multirow{2}{*}{$\begin{array}{c}\text { Standardized } \\
\text { Coefficients } \\
\text { Beta }\end{array}$} & \multirow[b]{2}{*}{$\mathrm{t}$} & \multirow[b]{2}{*}{ Sig. } & \multicolumn{2}{|c|}{$\begin{array}{l}\text { Collinearity } \\
\text { Statistics }\end{array}$} \\
\hline & & B & Std. Error & & & & Tolerance & VIF \\
\hline 6 & (Constant) & -1.269 & .600 & & -2.114 & .035 & & \\
\hline & Formal policies & -.253 & .082 & -.118 & -3.094 & .002 & .885 & 1.129 \\
\hline & Gender & -.224 & .060 & -.140 & -3.732 & .000 & .922 & 1.085 \\
\hline & Working hours & .132 & .013 & .401 & 9.856 & .000 & .782 & 1.279 \\
\hline & Tenure & -.020 & .005 & -.202 & -3.874 & .000 & .476 & 2.100 \\
\hline & Supervisory status & .013 & .006 & .117 & 2.274 & .023 & .486 & 2.057 \\
\hline & Income & .234 & .076 & .138 & 3.076 & .002 & .647 & 1.546 \\
\hline
\end{tabular}

a. Dependent Variable: Work demand

As can be seen in Table 4, the model 6 has been retained where $t$ values are significant for all predictor variables $(p<.05)$ indicating coefficients for all variables are not zero and thus predictors were making a significant contribution to the model.

$\mathrm{H}_{1 \mathrm{a}}$ that surmised that gender will have a significant impact on work demand was supported. The coefficient between gender and work demand is significantly negative $(\beta=-.22, t=-3.73, p<.001)$ implying that males have a significant positive impact on work demand and vice versa. Precisely, ceteris paribus, female respondents experience lesser work demand by -.224 than that of male counterparts. Similarly, $\mathrm{H}_{2}$ that working hours will be positively related to work demand was supported. The coefficient between working hours and work demand is significant $(\beta=.13, t=9.86, p<.001)$ indicating that working hours has a positive impact on work demand. For example, if the working hour increases by one hour, work demand will increase by .13 . Nonetheless, $\mathrm{H}_{3}$ that education will be positively related to work demand was not supported and dropped from the model $(\beta=-.11, t=-1.347, p<.18) . \mathrm{H}_{4}$ that predicted that income will be positively related to work demand was also supported. The coefficient between income and work demand is significant ( $\beta=.23, t=3.08, p<.01)$ indicating that a high level of income is a major contributor to work demand. The coefficient 
between supervisory status and work demand is significant $(\beta=.01, t=2.27, p<.05)$ and therefore $\mathrm{H}_{5}$ that supervisory status will be positively related to work demand was supported explaining that supervisory position has a significant positive effect on work demand. Next, the contention that tenure will be positively related to work demand $\left(\mathrm{H}_{6}\right)$ was also supported $(\beta=-.02, t=-3.87, p<.001) . \mathrm{H}_{7}$ that work-life policies will be negatively related to work demand was partially supported. The formal work-life policies have a significant impact on the reduction of work demand $(\beta=-.25$, $t=-3.09, p<.01)$ however, informal policies have not significantly contributed to work demand $(\beta=-.05, t=-.79, p=.43)$. Inter alia all predictor variables, working hours contributes more to this model because of its largest standardized coefficient (.40) in comparison with all other predictors. Overall, the model 6 is a robust model and the findings can be generalised beyond the sample.

In addition, independent sample $t$-test was performed to see work demand and working hours differences on gender, supervisory status and income. In tandem with $t$-test statistics, Cohen's $d$ was calculated and the values indicate a small-sized effect (.20), medium-sized effect (.50) and large-sized effect (.80) (Cohen, 1992). Table 5 presents the results of the independent sample $t$-test. The Levene's tests are not significant that met the assumption of equal variance ( $\mathrm{p}>.05)$. As can be seen in the same Table, as for work demand on average males $(M=4.13, S D=.77)$ reported a greater work demand than females $(M=3.71, S D=.76)$ and the difference is significant $t(567)=6.36, p<0.05$ emphasising a medium-sized effect $d=.53$. Similarly, employees with supervisory status experience a greater work demand $(M=4.08, S D=.63)$ than non-supervisory employees $(M=3.81, S D=.92)$ and the difference is significant $t(567)=-4.08, p<0.05$ emphasising a small-medium-sized effect $d=.35$. Employees who earned high-income experience high level of work demand $(M=4.06, S D=.71)$ than lower-income group $(M=3.73, S D=.91)$ and the difference is significant $t(567)=-4.33, p<0.05$ indicating a small-medium-sized effect $d=.36$.

Regarding the working hours, on average males $(M=43.58, S D=2.23)$ engage longer working hours than females counterparts $(M=42.26, S D=2.40)$ and the difference is significant $t(567)=6.67, p<0.05$ indicating a medium-sized effect $d=.57$. Consequently, the $\mathrm{H}_{1 \mathrm{~b}}$ predicted that males will spend longer working hours than that of females was supported. Further, the results reveal that employees who hold supervisor position work longer hours $(M=43.81$, $S D=2.21)$ than employees occupy non-supervisory roles $(M=42.18, S D=2.30)$ and the difference is significant $t(567)=-8.59, p<0.05$ emphasising a medium-large-sized effect $d=.72$. Similarly, employees with a high level of income work longer hours $(M=43.51, S D=2.21)$ than lower-income group $(M=41.99, S D=2.45)$ and the difference is also significant $t(567)=-7.37, p<0.05$ indicating a medium-large-sized effect $d=.65$.

Table 5. Gender, supervisory status and income differences on work demand and working hours

\begin{tabular}{llllcccccc}
\hline \multicolumn{1}{c}{ Variables } & & $N$ & $\mathrm{df}$ & Mean & $S D$ & $S E$ & $t$ & Sig. & Cohen's $d$ \\
\hline Work demand & Male & 333 & & 4.13 & .77 & .04 & & & \\
(Gender) & Female & 236 & 567 & 3.71 & .76 & .05 & 6.36 & .00 & .53 \\
Work demand & No & 272 & & 3.81 & .92 & .06 & & & \\
(Supervisory Status) & Yes & 297 & 567 & 4.08 & .63 & .04 & -4.08 & .00 & .35 \\
Work demand & Low & 179 & & 3.73 & .91 & .07 & & & \\
(Income) & High & 390 & 567 & 4.06 & .71 & .04 & -4.33 & .00 & .36 \\
Working hours per week & Male & 333 & & 43.58 & 2.23 & .12 & & & \\
(Gender) & Female & 236 & 567 & 42.26 & 2.40 & .16 & 6.67 & .00 & .57 \\
Working hours per week & No & 272 & & 42.18 & 2.30 & .14 & & & \\
(Supervisory Status) & Yes & 297 & 567 & 43.81 & 2.21 & .13 & -8.59 & .00 & .72 \\
Working hours per week & Low & 179 & & 41.99 & 2.45 & .18 & & & \\
(Income) & High & 390 & 567 & 43.51 & 2.21 & .11 & -7.37 & .00 & .65 \\
\hline
\end{tabular}

Source: Survey data

\section{Discussion}

The majority of work-family studies have been conducted in nations with individualist culture and the resultant prevalent conceptualisations and models mostly reflect such cultural contexts. Unfortunately, little work has been carried out in countries with collectivist culture and the research that has been done has applied the conceptualisations and models developed in individualist cultural nations without question. This study, therefore, 
focused on a collectivist cultural nation, Sri Lanka, to identify the factors determining work demand.

As can be seen in the model, of the predictors of work demand, working hours had the largest impact on work demand, followed by tenure, gender, income, formal work-life policies and supervisory status (number of employees reporting), the findings are consistent with previous studies (e.g. Boyar et al., 2008; Russell et al., 2009). All the predictors accounted for $27.1 \%$ of variance in work demand. The respondents report a greater amount of work demand indicating a greater amount of sacrifice on their family for work (Yang et al., 2000). Moreover, since interpersonal relationships and trust are crucial at the workplace with collectivist culture in which employee engages after-hour events, work demand is high (Aycan, 2008) and the hierarchical structure is the source of work demand (Shockley et al., 2017). Further, in developing countries, there might be pressure for greater productivity in the workplace leading to high demand at work (Joplin et al., 2003) and upward social comparisons in collectivist culture could also contribute to high work demand (see Trefalt, Drnovšek, Svetina-Nabergoj, \& Adlešič, 2013). This study found that employees work long hours per week $(\mathrm{M}=43.03)$ that might be attributed to the higher unemployment rate in less developed economies where they protect their job and grasp the opportunities for uplifting their life. The finding is in line with a recent study that found hours worked and overtime hours are the major predictors of work demand (Haar et al., 2019). Men spent significantly longer working hours than women; however, women working hours were greater in comparison with the developed world (Cousins \& Tang, 2004). Based on socio-cultural expectations theory, spending more time in an opposite domain has a greater psychological impact on a person than spending time in his/her own domain (Gutek, Searle, \& Klepa, 1991). And women in collectivist culture would suffer significantly than men due to the high level of family responsibilities (Kinnunen \& Mauno, 1998). Tenure (number of years) was significantly negatively related to work demand as employees attuned to their work. Albeit income and number of employees reporting increase work demand, the presence of formal work-life policies attenuates the effect of the work demand. Importantly, organisation formal work-life policies viz., flexible working arrangements, compressed working week, eldercare, working at home found in several seminal studies conducted in the West were not found to be present in Sri Lanka. Notwithstanding, some formal work-life polities viz., paid leave for dealing with family problems; maternity leave and paternity leave are more prevalent. Overall, men reported significantly greater amounts of work demand than women indicating the prevalence nature of traditional gender role ideology. In nations with egalitarian cultures women earn money and contribute to the economic benefits of family meanwhile men and women share family responsibilities (Ruppanner \& Huffman, 2014). Nonetheless, in inequality cultures, even though women earn money and contribute to economic benefits of family, their family responsibilities are not reduced explaining that women did not perceive their work role as their central role (see Livingston \& Judge, 2008).

The employees with supervisory status experience a greater work demand than non-supervisory employees implying a greater amount of job duties, responsibilities and accountabilities assigned to the supervisory personnel. Employees who earned high-income reports a high-work demand explaining that the high-income earners spent more time on work and the findings are similar to that of Lambert, Lambert, and Ito's (2004) study that found a negative correlation between income level and workplace stressor. On balance, policies and strategies buffering the work demand in developing countries are limited and therefore, it makes work and family domain more competitive (e.g. Annink et al., 2016).

\subsection{Implications}

A high level of work demand is detrimental to work-life balance (Haar et al., 2019). In a collective culture, family care is left to the responsibilities of families and the minimal organisational supports translate into a high level of interference on work matters (Mortazavi, Pedhiwala, Shafiro, \& Hammer, 2009). Since the effects of work-family imbalance could be buffered by the organisational supports such as flexible work arrangement (e.g. Allen, Johnson, Kiburz, \& Shockley, 2013), part-time working (e.g. Beham, Präg, \& Drobnič, 2012), childcare (e.g. Beauregard \& Henry 2009), eldercare (e.g. Beauregard \& Henry 2009) and employee health and wellness benefits (e.g. Beauregard \& Henry 2009), the present study stresses a compelling need for the policies to ease the burden of work demand. However, organisations should be careful in transforming established policies and practices from one country to another (Annor \& Burchell, 2018). The organisations can also take initiative to redesign the job: for instance, enjoyable jobs, including greater autonomy, skills used, variety of interesting piece of jobs etc., in which employees mind will not working harder. The study further found a greater work demand for both men and women. It is believed that men are socialised to cope with stressor in the work demand, nonetheless, working women might be expecting greater work support to alleviate demand at work to engage with their primary domain of family demand like childcare, eldercare, and all other household chores. In addition, this study found the number of working hours directly strongly impact on work demand. Since collectivists value more to the family, working hours might have 
serious concerns (Wharton \& Blair-Loy, 2006). It is recommended to the organisation to place a cap on the number of working hours per week to take advantages of work-family balance and ipso facto organisations in less developed economies can scale down the number of unemployed in the market, leading to reduce poverty and make optimum use of the variety of human talents. As discussed earlier, according to the socio-cultural expectations theory, time spent working in the opposite domain could have a greater psychological impact (Kinnunen \& Mauno, 1998). Therefore, women in collectivist culture could perceive more psychological burden by spending more time at the workplace. Similarly, since working women responsibilities in the family have not been reduced, called "normalization of the double day" (Glazer, 1980, p. 79), the pervading equal policies for both men and women in the workplace have been questioned. In addition, a set of dual expectations becomes breeding ground for women's exit from the workforce. Consequently, it behoves HR managers and practitioners to design well-informed HR policies for negating the psychological strain and adverse effects on women well-being. Supervisory status (number of employees reporting) and income were found to causes deleterious effect on work demand suggesting that reducing the span of control could curb the burden of work demand, as well as providing more opportunities for promotion within the company. Furthermore, this research urges the policymakers, practitioners and members of organisations to collaborate in balancing work and family in nations with collectivist cultures. On balance, the findings emphasise pressing needs for reducing the burden of work demand. Some gender-based HR policies might also help promote a healthy workplace environment and to increase women's labour force participation.

\subsection{Limitations and Directions for Future Research}

Although the study has made strong theoretical contributions and useful practical implications, the study is not without limitations. The study's argument is based on the cultural variations in countries, mainly individualism and collectivism, however, there is plausible for the cultural values among the individuals within the same country (Triandis \& Gelfand, 1998). Therefore, the future studies must measure the cultural variation and recommended to expand the study at least two-country comparison that helps ascertain convergence and divergence of cultural variations in the determinants of work demand. Importantly, the effects and strengths of work demand on employees and organisations are contingent on cultural variations and therefore findings from one cultural setting cannot be applied to other cultural settings. Consequently, future research studies should be warranted for investigating the consequences of work demand in collectivist and transitioning economies. For instance, stigma on upward social comparisons and extensive choices in transitioning economies is pervading and therefore, the consequence of work demand might not be great concerns (see Trefalt et al., 2013). Another important limitation of the study is its design, cross-sectional, in which making casual relationship is problematic. Undertaking study at a single period in time can only reflect that time per se and the social and economic and industrial context in Sri Lanka is changing rapidly, thus the need for longitudinal research. The findings of this current study were based on a self-reported measured and thus might be subject to bias (e.g. ego flattering) or where respondents might be reluctant to bring their work-related matters to light. Thus, a more detailed qualitative study is warranted. The present study has focused on banking organisations as a microcosm of a higher status occupation. Therefore, there was a methodological limitation in generalizing findings to the other sectors or other similar nations (country effect). Consequently, a more detailed study across organisations, occupations and nations with similar culture is warranted for further validation, replication and generalisation. Moreover, the study did not investigate the role of government laws and regulations governing both the organisation and employees.

\section{References}

Allen, T. D. (2001). Family-supportive work environments: The role of organizational perceptions. Journal of Vocational Behavior, 58(3), 414-435. https://doi.org/10.1006/jvbe.2000.1774

Allen, T. D., Johnson, R. C., Kiburz, K. M., \& Shockley, K. M. (2013). Work-family conflict and flexible work arrangements: Deconstructing flexibility. Personnel Psychology, 66(2), 345-376. https://doi.org/10.1111/peps.12012

Annink, A., Den Dulk, L., \& Steijn, B. (2016). Work-family conflict among employees and the self-employed across Europe. Social Indicators Research, 126(2), 571-593. https://doi.org/10.1007/s11205-015-0899-4

Annor, F., \& Burchell, B. (2018). A cross-national comparative study of work demands/support, work-to-family conflict and job outcomes: Ghana versus the United Kingdom. International Journal of Cross Cultural Management, 18(1), 53-72. https://doi.org/10.1177/1470595817746195

Aycan, Z. (2008). Cross-cultural perspectives to work-family conflict. In K. Korabik, \& D. Lero (Eds.), Handbook of Work-Family Conflict (pp. 359-371). London: Cambridge University Press. 
Bailey, D. E., \& Kurland, N. B. (2002). A review of telework research: Findings, new directions, and lessons for the study of modern work. Journal of Organizational Behavior, 23(4), 383-400. https://doi.org/10.1002/job.144

Baltes, B. B., Briggs, T. E., Huff, J. W., Wright, J. A., \& Neuman, G. A. (1999). Flexible and compressed workweek schedules: A meta-analysis of their effects on work-related criteria. Journal of Applied Psychology, 84(4), 496-513. https://doi.org/10.1037/0021-9010.84.4.496

Beauregard, T. A., \& Henry, L. C. (2009). Making the link between work-life balance practices and organizational performance. Human Resource Management Review, 19(1), 9-22. https://doi.org/10.1016/j.hrmr.2008.09.001

Beham, B., Präg, P., \& Drobnič, S. (2012). Who's got the balance? A study of satisfaction with the work-family balance among part-time service sector employees in five western European countries. The International Journal of Human Resource Management, 23(18), 3725-3741. https://doi.org/10.1080/09585192.2012.654808

Behson, S. J. (2002). Coping with family-to-work conflict: The role of informal work accommodations to family. Journal of Occupational Health Psychology, 7(4), 324-341. https://doi.org/10.1037/1076-8998.7.4.324

Bhave, D. P., Kramer, A., \& Glomb, T. M. (2013). Pay satisfaction and work-family conflict across time. Journal of Organizational Behavior, 34(5), 698-713. https://doi.org/10.1002/job.1832

Blumberg, B., Cooper, D., \& Schindler, P. (2008) Business Research Method (2nd ed., European ed.). Maidenhead: McGraw-Hill Education.

Boyar, S. L., Carr, J. C., Mosley Jr, D. C., \& Carson, C. M. (2007). The development and validation of scores on perceived work and family demand scales. Educational and Psychological Measurement, 67(1), 100-115. https://doi.org/10.1177/0013164406288173

Boyar, S. L., Maertz Jr, C. P., Mosley Jr, D. C., \& Carr, J. C. (2008). The impact of work/family demand on work-family conflict. Journal of Managerial Psychology, 23(3), 215-235. https://doi.org/10.1108/02683940810861356

Choi, J. (2008). Work and family demands and life stress among Chinese employees: The mediating effect of work-family conflict: Work and family demands and life stress among Chinese employees. The International Journal of Human Resource Management, 19(5), 878-895. https://doi.org/10.1080/09585190801993885

Clark, S. C. (2001). Work cultures and work/family balance. Journal of Vocational Behavior, 58(3), $348-365$. https://doi.org/10.1006/jvbe.2000.1759

Cohen, J. (1992). Statistical power analysis. Current Directions in Psychological Science, 1(3), 98-101. https://doi.org/10.1111/1467-8721.ep10768783

Colquitt, J. A., Conlon, D. E., Wesson, M. J., Porter, C. O., \& Ng, K. Y. (2001). Justice at the millennium: a meta-analytic review of 25 years of organizational justice research. Journal of Applied Psychology, 86(3), 425-445. https://doi.org/10.1037/0021-9010.86.3.425

Cousins, C. R., \& Tang, N. (2004). Working time and work and family conflict in the Netherlands, Sweden and the UK. Work, Employment and Society, 18(3), 531-549. https://doi.org/10.1177/0950017004045549

Department of Census and Statistics. (2013). Sri Lanka Labour Force Survey. Quarterly report 2013 [Online]. Retrived 5 January 2019, from http://www.statistics.gov.lk/samplesurvey/2013 q4report.pdf

Dooley, L. M., \& Lindner, J. R. (2003). The handling of nonresponse error. Human Resource Development Quarterly, 14(1), 99-110. https://doi.org/10.1002/hrdq.1052

Duxbury, L. E., \& Higgins, C. A. (1991). Gender differences in work-family conflict. Journal of Applied Psychology, 76(1), 60-74. https://doi.org/10.1037/0021-9010.76.1.60

Field, A. (2013). Discovering statistics using IBM SPSS statistics (4th ed.). London: Sage.

Frone, M. R. (2000). Work-family conflict and employee psychiatric disorders: The national comorbidity survey. Journal of Applied Psychology, 85(6), 888-895. https://doi.org/10.1037/0021-9010.85.6.888

Glazer, N. (1980). Overworking the working woman: The double day in a mass magazine. Women's Studies International Quarterly, 3(1), 79-93. https://doi.org/10.1016/S0148-0685(80)92675-5

Goff, S. J., Mount, M. K., \& Jamison, R. L. (1990). Employer supported child care, work/family conflict, and absenteeism: A field study. Personnel Psychology, 43(4), https://doi.org/10.1111/j.1744-6570.1990.tb00683.x 
Goodstein, J. (1995). Employer involvement in eldercare: An organizational adaptation perspective. Academy of Management Journal, 38(6), 1657-1671. https://doi.org/10.5465/256848

Gutek, B. A., Searle, S., \& Klepa, L. (1991). Rational versus gender role explanations for work-family conflict. Journal of Applied Psychology, 76(4), 560-568. https://doi.org/10.1037/0021-9010.76.4.560

Haar, J. M., Sune, A., Russo, M., \& Ollier-Malaterre, A. (2019). A cross-national study on the antecedents of work-life balance from the fit and balance perspective. Social Indicators Research, 142(1), 261-282. https://doi.org/10.1007/s11205-018-1875-6

Hassan, Z., Dollard, M. F., \& Winefield, A. H. (2010). Work-family conflict in East vs Western countries. Cross Cultural Management: An International Journal, 17(1), 30-49. https://doi.org/10.1108/13527601011016899

Hobfoll, S. E. (1989). Conservation of resources: A new attempt at conceptualizing stress. American Psychologist, 44(3), 513-524. https://doi.org/10.1037/0003-066X.44.3.513

Hofstede, G., Hofstede, G. J., \& Minkov, M. (2010). Cultures and organizations: Software of the Mind (3rd ed.). New York: McGraw-Hill.

Jin, J. F., Ford, M. T., \& Chen, C. C. (2013). Asymmetric differences in work-family spillover in North America and China: Results from two heterogeneous samples. Journal of Business Ethics, 113(1), 1-14. https://doi.org/10.1007/s10551-012-1289-3

Joplin, J. R., Shaffer, M. A., Francesco, A. M., \& Lau, T. (2003). The macro-environment and work-family conflict: Development of a cross cultural comparative framework. International Journal of Cross Cultural Management, 3(3), 305-328. https://doi.org/10.1177/1470595803003003004

Kinnunen, U., \& Mauno, S. (1998). Antecedents and outcomes of work-family conflict among employed women and men in Finland. Human Relations, 51(2), 157-177. https://doi.org/10.1177/001872679805100203

Kodom-Wiredu, J. K. (2019). The Relationship between Firefighters' Work Demand and Work-related Musculoskeletal Disorders: The Moderating Role of Task Characteristics. Safety and Health at Work, 10(1), 61-66. https://doi.org/10.1016/j.shaw.2018.05.004

Lafreniere, S. L., \& Longman, K. A. (2008). Gendered realities and women's leadership development: Participant voices from faith-based higher education. Christian Higher Education, 7(5), 388-404. https://doi.org/10.1080/15363750802171081

Lambert, V. A., Lambert, C. E., \& Ito, M. (2004). Workplace stressors, ways of coping and demographic characteristics as predictors of physical and mental health of Japanese hospital nurses. International Journal of Nursing Studies, 41(1), 85-97. https://doi.org/10.1016/S0020-7489(03)00080-4

Livingston, B. A., \& Judge, T. A. (2008). Emotional responses to work-family conflict: An examination of gender role orientation among working men and women. Journal of Applied Psychology, 93(1), 207-216. https://doi.org/10.1037/0021-9010.93.1.207

Lu, L., Gilmour, R., Kao, S. F., \& Huang, M. T. (2006). A cross-cultural study of work/family demands, work/family conflict and wellbeing: the Taiwanese vs British. Career Development International, 11(1), 9-27. https://doi.org/10.1108/13620430610642354

Martinengo, G., Jacob, J. I., \& Hill, E. J. (2010). Gender and the work-family interface: Exploring differences across the family life course. Journal of Family Issues, 31(10), 1363-1390. https://doi.org/10.1177/0192513X10361709

Mennino, S. F., Rubin, B. A., \& Brayfield, A. (2005). Home-to-job and job-to-home spillover: The impact of company policies and workplace culture. The Sociological Quarterly, 46(1), 107-135. https://doi.org/10.1111/j.1533-8525.2005.00006.x

Michel, J. S., Kotrba, L. M., Mitchelson, J. K., Clark, M. A., \& Baltes, B. B. (2011). Antecedents of work-family conflict: A meta-analytic review. Journal of Organizational Behavior, 32(5), 689-725. https://doi.org/10.1002/job.695

Milliken, F. J., Martins, L. L., \& Morgan, H. (1998). Explaining organizational responsiveness to work-family issues: The role of human resource executives as issue interpreters. Academy of Management Journal, 41(5), 580-592. https://doi.org/10.5465/256944

Mortazavi, S., Pedhiwala, N., Shafiro, M., \& Hammer, L. (2009). Work-family conflict related to culture and gender. 
Community, Work \& Family, 12(2), 251-273. https://doi.org/10.1080/13668800902779023

Nomaguchi, K. M. (2009). Change in work-family conflict among employed parents between 1977 and 1997. Journal of Marriage and Family, 71(1), 15-32. https://doi.org/10.1111/j.1741-3737.2008.00577.x

Ruppanner, L., \& Huffman, M. L. (2014). Blurred boundaries: Gender and work-family interference in cross-national context. Work and Occupations, 41(2), 210-236. https://doi.org/10.1177/0730888413500679

Russell, H., O'Connell, P. J., \& McGinnity, F. (2009). The impact of flexible working arrangements on work-life conflict and work pressure in Ireland. Gender, Work \& Organization, 16(1), 73-97. https://doi.org/10.1111/j.1468-0432.2008.00431.x

Schieman, S., \& Glavin, P. (2011). Education and work-family conflict: Explanations, contingencies and mental health consequences. Social Forces, 89(4), 1341-1362. https://doi.org/10.1093/sf/89.4.1341

Schieman, S., Whitestone, Y. K., \& Van Gundy, K. (2006). The nature of work and the stress of higher status. Journal of Health and Social Behavior, 47(3), 242-257. https://doi.org/10.1177/002214650604700304

Shaffer, M. A., Joplin, J. R., \& Hsu, Y. S. (2011). Expanding the boundaries of work-family research: A review and agenda for future research. International Journal of Cross Cultural Management, 11(2), 221-268. https://doi.org/10.1177/1470595811398800

Shockley, K. M., Douek, J., Smith, C. R., Peter, P. Y., Dumani, S., \& French, K. A. (2017). Cross-cultural work and family research: A review of the literature. Journal of Vocational Behavior, 101, 1-20. https://doi.org/10.1016/j.jvb.2017.04.001

Sirgy, M. J., \& Lee, D. J. (2018). Work-life balance: An integrative review. Applied Research in Quality of Life, 13(1), 229-254. https://doi.org/10.1007/s11482-017-9509-8

Sok, J., Blomme, R., \& Tromp, D. (2014). Positive and negative spillover from work to home: The role of organizational culture and supportive arrangements. British Journal of Management, 25(3), 456-472. https://doi.org/10.1111/1467-8551.12058

Sweeney, P. D., \& McFarlin, D. B. (1993). Workers' evaluations of the" ends" and the" means": An examination of four models of distributive and procedural justice. Organizational Behavior and Human Decision Processes, 55(1), 23-40. https://doi.org/10.1006/obhd.1993.1022

Syed, S., Arain, G. A., Schalk, R., \& Freese, C. (2015). Balancing work and family obligations in Pakistan and the Netherlands: A comparative study. Global Business and Organizational Excellence, 34(5), 39-52. https://doi.org/10.1002/joe.21625

Thalgodapitiya, R., \& Bhoumik, A. (2012). The Sri Lankan Banking Sector: Special Report, FitchRatings, 27 January [Online]. Retrieved 4 March 2019, from file:///C:/Users/kenga/Downloads/Banking\%20sector\%20report\%2027\%20JAN\%202012\%20(4).pdf

Trefalt, Š., Drnovšek, M., Svetina-Nabergoj, A., \& Adlešič, R. V. (2013). Work-life experiences in rapidly changing national contexts: Structural misalignment, comparisons and choice overload as explanatory mechanisms. European Management Journal, 31(5), 448-463. https://doi.org/10.1016/j.emj.2013.04.006

Triandis, H. C., \& Gelfand, M. J. (1998). Converging measurement of horizontal and vertical individualism and collectivism. Journal of Personality and Social Psychology, 74(1), 118-128. https://doi.org/10.1037/0022-3514.74.1.118

Wallace, R. O., \& Mellor, C. J. (1988). Nonresponse bias in mail accounting surveys: a pedagogical note. The British Accounting Review, 20(2), 131-139. https://doi.org/10.1016/0890-8389(88)90036-4

Werner, S., Praxedes, M., \& Kim, H. G. (2007). The reporting of nonresponse analyses in survey research. Organizational Research Methods, 10(2), 287-295. https://doi.org/10.1177/1094428106292892

Wharton, A. S., \& Blair-Loy, M. (2006). Long work hours and family life: A cross-national study of employees' concerns. Journal of Family Issues, 27(3), 415-436. https://doi.org/10.1177/0192513X05282985

Yang, N., Chen, C. C., Choi, J., \& Zou, Y. (2000). Sources of work-family conflict: A Sino-US comparison of the effects of work and family demands. Academy of Management Journal, 43(1), 113-123. https://doi.org/10.5465/1556390

Zedeck, S., \& Mosier, K. L. (1990). Work in the family and employing organization. American Psychologist, 45(2), 240-251. https://doi.org/10.1037/0003-066X.45.2.240 